\section{Revista Brasileira de Administração Científica}

Brazilian Journal of Scientific Administration

Abr a Jun 2021 - v.12 - n.2
RBADM

ISSN: 2179-684X

\title{
Inovação, empreendedorismo e inclusão social: o caso inovador de uma Gelateria em Aracaju/SE
}

O empreendedorismo tem sido uma válvula de escape crescente e atual para os brasileiros nos últimos anos. Mas apesar desse crescimento, seja por necessidade ou por oportunidade ainda existem diversas lacunas no que se refere aos conceitos de inovação, crescimento econômico, competitividade e o mais raro de todos, a inclusão social. Compreende-se que, para todo empreendedor, os desafios para se inserir no mercado são enormes. Pensando nisso, ao analisar a atitude determinada e empreendedora do Empresário e Gestor da 'Alfa', que é surdo desde que nasceu e fundou a primeira gelateria com colaboradores surdos na cidade de Aracaju/SE, surgiu a vontade de pesquisar a fundo a sua iniciativa de empreender e inserir colaboradores surdos em sua empresa, a fim de identificar seus desafios profissionais e pessoais no princípio e atualmente. Foi pensando nisso que essa pesquisa foi desenvolvida com o objetivo geral de identificar o perfil e comportamento empreendedor do gestor da Gelateria 'Alfa', Empresário e Gestor da 'Alfa'. Os específicos foram: avaliar seu processo de recrutamento e seleção; averiguar o nível de satisfação de seus colaboradores; observar a satisfação dos seus clientes; verificar o atendimento e controle de qualidade de seus produtos e serviços. A metodologia foi pautada por pesquisa descritiva, orientado para o estudo de caso, realizada coleta de dados por meio de entrevista via WhatsApp e, presencialmente, por intérprete. Dentre os resultados, foram destaque a qualificação profissional, expansão do empreendimento e sucesso no negócio.

Palavras-chave: Empreendedorismo; Inclusão social; Surdo; Gelateria.

\section{Innovation, entrepreneurship and social inclusion: the innovative case of a Gelateria in Aracaju/SE}

\begin{abstract}
Entrepreneurship has been a growing and current escape valve for Brazilians in recent years. But despite this growth, whether out of necessity or opportunity, there are still several gaps with regard to the concepts of innovation, economic growth, competitiveness and the rarest of all, social inclusion. It is understood that, for every entrepreneur, the challenges to enter the market are enormous. Thinking about it, when analyzing the determined and entrepreneurial attitude of the businessman Empresário e Gestor da 'Alfa', who has been deaf since he was born and founded the first gelateria with deaf employees in the city of Aracaju/SE, the desire to deeply investigate his initiative to enter and enter deaf employees in your company, in order to identify your professional and personal challenges in the beginning and today. It was with this in mind that this research was developed with the general objective of identifying the profile and entrepreneurial behavior of the manager of Gelateria 'Alfa', Empresário e Gestor da 'Alfa'. The specifics were: to evaluate their recruitment and selection process; ascertain the level of satisfaction of its employees; observe the satisfaction of its customers; check the attendance and quality control of your products and services. The methodology was guided by descriptive research, oriented to the case study, data collection was carried out through an interview via WhatsApp and, in person, by an interpreter. Among the results, professional qualification, expansion of the enterprise and business success were highlighted.
\end{abstract}

Keywords: Entrepreneurship; Social inclusion; Deaf; Gelateria.

Topic: Empreendedorismo

Reviewed anonymously in the process of blind peer.
Received: 07/04/2021

Approved: 04/06/2021
Silvia Manoela Santos de Jesus

Universidade Federal de Sergipe, Brasil

http://lattes.cnpq.br/5781099018176442

http://orcid.org/0000-0001-5723-6872

profasilviamanoela@hotmail.com

Amanda Souza Costa

Centro Universitário Ages, Brasil

http://lattes.cnpq.br/9667711646917905

amandinhaa costaa12@hotmail.com

Edivaldo Rabelo de Menezes

Universidade do Estado do Rio Grande do Norte, Brasil

http://lattes.cnpq.br/2541866097413422

http://orcid.org/0000-0002-7144-3795

professoredivaldorabelo@gmail.com

\author{
Tiago de Melo Ramos (ic \\ Universidade Federal de Sergipe, Brasil \\ http://lattes.cnpq.br/2779127504019738 \\ http://orcid.org/0000-0002-6500-557X \\ tiagoed.f@hotmail.com
}

Referencing this:

JESUS, S. M. S.; COSTA, A. S.; MENEZES, E. R.; RAMOS, T. M.. Inovação, empreendedorismo e inclusão social: o caso inovador de uma Gelateria em Aracaju/SE. Revista Brasileira de Administração Científica, v.12, n.2, p.90-99, 2021. DOI:

http://doi.org/10.6008/CBPC2179-684X.2021.002.0008 


\section{INTRODUÇÃO}

Os empreendedores são responsáveis por promover e dinamizar a economia no país, exercendo um papel econômico e social muito importante. Schumpeter (1988) fala que o empreendedorismo é uma alternativa para gerar emprego e criar oportunidades de negócios o que possibilita desenvolvimento econômico para o país. Considerando as transformações ocorridas pela grande evolução econômica, fazem com que os empreendedores impulsionem a busca de novos produtos e serviços, ampliando assim o capital.

Em grande parte dos casos a iniciativa de se tornar um empreendedor surge a partir da necessidade, devido ao alto índice de desemprego no país, e então as pessoas de alguma forma buscam uma fonte renda extra, vendendo um produto/serviço em casa, na garagem, nas ruas, nas praias, de porta em porta, nas redes sociais, entre outros meios. O fato é que apesar dessa crescente iniciativa, nem todos conseguem se consolidar no mercado, devido à falta de planejamento e estratégia. E, então, surge a diferenciação entre o autônomo, o empresário e o empreendedor.

O Empreendedor pode ser autônomo e empresário do seu próprio negócio, ou até mesmo do negócio de outra pessoa, mas o autônomo e o empresário nem sempre serão empreendedores. 0 empreendedorismo gerencia alterações que envolvem inovação e riscos gerando resultados positivos, e tudo exige vontade, talento e criatividade.

O autônomo geralmente atua por necessidade ou como fonte renda extra e não tem perspectiva de expansão. O empresário geralmente é um termo formal e aplicado a quem tem um CNPJ, compra e vende, contrata e demite, lança notas e paga impostos, apegado aos velhos paradigmas de gerenciamento engessado, não assume riscos, não busca inovação, não investe em capital humano e tudo que interessa é fluxo de caixa positivo no fim do mês. Claro que todos esses conceitos citados, não estão sendo generalizados, são feitos com base na nossa realidade e para toda regra há uma exceção.

Compreende-se que, para todo empreendedor, os desafios para se inserir no mercado são enormes. É muito comum falar, estudar e praticar o empreendedorismo quando não se tem nenhuma limitação física que dificulte a sua inserção nele. Pensando nisso, ao analisar a atitude determinada e empreendedora do Empresário e Gestor da 'Alfa', que é surdo desde que nasceu e fundou a primeira gelateria com colaboradores surdos na cidade de Aracaju - SE, surgiu a vontade de pesquisar a fundo a sua iniciativa de empreender e inserir colaboradores surdos em sua empresa, a fim de identificar seus desafios profissionais e pessoais no princípio e atualmente. Afinal, as primeiras dificuldades do surdo começam na infância, com a comunicação e compreensão da família, depois a dificuldade de encontrar uma escola inclusiva, que tenha profissionais fluentes em LIBRAS, profissionais da saúde e a inclusão social e relacionamento com as pessoas ao seu redor, é preciso muita atenção, pois se a criança surda não tiver tudo isso como base, se torna um adulto reprimido e isolado, porque se sente incompreendido por todos ao seu redor, e isso o impede de desenvolver habilidades que todo ser humano precisa.

Foi pensando nisso que essa pesquisa foi desenvolvida com o objetivo geral de identificar o perfil e comportamento empreendedor do gestor da Gelateria 'Alfa', Empresário e Gestor da 'Alfa'. Os específicos 
foram: avaliar seu processo de recrutamento e seleção; averiguar o nível de satisfação de seus colaboradores; observar a satisfação dos seus clientes; verificar o atendimento e controle de qualidade de seus produtos e serviços.

\section{REVISÃO TEÓRICA}

\section{Empreendedorismo}

Após várias tentativas de estabilização da economia e controle da crise, o empreendedorismo se tornou uma alternativa com retorno bastante positivo para o brasileiro e uma oportunidade de reinvenção para muitos empresários. O mundo tem passado por diversas transformações, resultando na mudança de comportamento do consumidor e exigindo a adaptação do mercado as constantes mudanças e transformações. Aquele que consegue desenvolver, criar, inovar em meio à crise é denominado empreendedor.

Os empreendedores são pessoas diferenciadas, que possuem motivação singular, apaixonadas pelo o que fazem, não se contentam em ser mais um na multidão, querem ser reconhecidas e admiradas, referenciadas e imitadas, querem deixar um legado (DORNELAS, 2012)

Existem inúmeras definições para o empreendedorismo, na visão de Dornelas (2012) o empreendedorismo é o envolvimento de pessoas e processos que, em conjunto, levam a transformação de ideias em oportunidades. Em outras palavras, é planejar (ou não) e pôr uma ideia em ação.

Franco et al. (2016) afirma que na verdade, o empreendedor consegue fazer as coisas acontecerem por ser dotado de sensibilidade para os negócios, tino financeiro e capacidade de identificar e aproveitar oportunidades, nem sempre claras e definidas. E foi com essa sensibilidade e anseio por independência que Empresário e Gestor da 'Alfa' fez as coisas acontecerem, transformando suas ideias em realidade para benefício próprio e para o benefício da sociedade e da comunidade surda.

Há características do empreendedor, são elas: a necessidade de realização, disposição para assumir riscos e autoconfiança (FRANCO et al., 2016). A necessidade de realização do fundador da 'Alfa', sua uniformidade com status quo e assumir responsabilidades e riscos mensuráveis e imensuráveis e sua autoconfiança ao acreditar em sua ideia, o colocou em posição de destaque, empreendedor nato. Um bom negócio é aquele que tem feitio pessoal, a sua cara, o seu jeito. O negócio deve se ajustar ao empreendedor como se fosse feito sob medida. O novo negócio tem que apresentar um DNA, mas deve coincidir também com o mercado. Sem dúvidas 'Alfa' tem o DNA de Empresário e Gestor da 'Alfa', seu jeito e sua cara, o tornando um modelo de negócio único e diferenciado, coincidindo com o mercado de Aracaju - SE e atingindo o público de outros lugares.

Nas palavras de Braum (2019), a necessidade de realização pode ser definida como o alto desejo de realização que explica o comportamento dos empreendedores pode ser resumido em desejo das pessoas pela responsabilidade das tomadas de decisões pessoais. A preferência para as decisões que envolvam um 
grau de risco moderado e o interesse dessas pessoas em conhecimento concreto dos resultados das decisões tomadas.

Mariuzza (2019) discute em suas pesquisas elementos que agem como propulsores ao empreendedorismo, como exemplo a base social, influência e estímulos da família, amigos, mentores e a própria história de vida, mas ressalvam que cada elemento deve ser analisado de maneira isolada, pois a criação de um negócio depende de vários fatores. O desemprego também é uma variável citada pela literatura como desencadeador para o empreendedorismo.

\section{Inclusão Social}

A inclusão social é classificada como um direito humano. É o conjunto de meios e ações que visam oferecer oportunidades iguais de acesso a bens e serviços a todos, combatendo a exclusão da vida em sociedade, provocadas pelas diferenças de classe, gênero, cor, sexualidade, educação e deficiências. Tratar da inclusão social é importante, pois permite a democratização dos direitos e inserção do indivíduo em todo o meio social. O meio social começa na família, logo na infância, e se estende à escola, à saúde, à relação e comunicação com outras pessoas, ao ensino superior e ao trabalho. Ela pode ser definida a partir de um conjunto de atividades e mecanismos que asseguram a participação de todos, mesmo com alguns avanços e seguridade da lei, a inclusão só pode ser efetivada de fato pelo próprio meio social, dando voz e oportunidade a essas minorias. Segundo Mazzotta (2008) a inclusão é a convivência respeitosa de uns com os outros, e é essencial para que cada indivíduo possa se constituir como pessoa ou como sujeito e, assim, não venha ser meramente equiparado a qualquer coisa ou objeto.

A Lei 13.146/2015, conhecida como a Lei da Inclusão, foi aprovada em 06 de julho de 2015, ofertando garantias para o equiparo a pessoas com deficiência diante da sociedade. Em conceito claro, a Lei considera como deficiência, todo aquele que tem impedimento a longo prazo de natureza, física, mental, intelectual ou sensorial, dispondo da participação efetiva de todos, em todo convívio social de forma igualitária. As deficiências sensoriais são aquelas que afetam um dos cinco sentidos, causando a ausência total ou parcial que incapacita a sua utilização plena, são as mais comuns como exemplo a cegueira e a surdez.

Em se tratando do surdo, Guarinello (2000) destaca a família como a primeira escola responsável pelas capacidades desenvolvidas das crianças. O papel da família é ressaltado como cooperador para o processo do desenvolvimento do surdo, no sentido de garantir a esse indivíduo um futuro de independência e produtividade na sociedade. Também é concebida à escola e à comunidade como parceiras, desenvolvendo no surdo a sua autoestima e independência para definir seu estilo de vida.

O papel fundamental da escola é lecionar a educação da sociedade, desenvolvendo exemplos de cidadãos para formação e interação com a sociedade. Raiça (2008) afirma, que dessa forma, a educação não envolve apenas a escolarização e alfabetização de maneira isolada, e direcionada apenas a instituições de ensino, mas também como o processo de formação pessoal do indivíduo para seu desenvolvimento humano e social. Isso dá na troca de conhecimento não só de professor para aluno, mas de indivíduo para indivíduo, 
todos os dias, a todo momento, os seres humanos aprendem uns com os outros, desenvolvendo então uma personalidade, costume, crença, cultura, vocação e propósito.

O grande dilema é fazer com que a sociedade compreenda, que esse direito é para todos, e quando se fala no todo, envolve o ouvinte e o surdo, e não de forma isolada. A comunidade surda precisa estar inserida, a adaptação tem que vir dos ouvintes para o surdo, e não o contrário. Os surdos não devem ser segregados e limitados a aprender e se desenvolver entre eles, mas sim, devem aprender e se desenvolver dentro do todo.

Em afirmação à citação de Gorczevski et al. (2013), a educação é o mais importante instrumento de inclusão social para a consolidação da cidadania e concretização dos direitos humanos, sendo imprescindível para a tomada de consciência de si mesmo e de sua importância para a comunidade.

O desemprego é a realidade de muitos brasileiros, cada dia mais as empresas buscam contratar pessoas capacitadas para exercer a função que lhe é ofertada, em uma ótica mais profunda, essa realidade é ainda mais dura quando se trata da contratação de deficientes. Isso seria quase impossível se não fosse a Lei Brasileira de Inclusão (LBP), em que diz que as empresas devem ter entre $2 \%$ a $5 \%$ do seu quadro de funcionários composto por pessoas com deficiência, ainda assim, muitos desses cargos ofertados são classificados como subempregos, e, infelizmente, as empresas ignoram os candidatos surdos por considerar inviável a comunicação com os mesmos (BRASIL, 2001).

Conforme Amaral (2004), nenhum indivíduo está imune ao desconforto, medo, insegurança, frente ao desconhecido e, até segunda ordem, à deficiência ainda é bastante desconhecida da população em geral. Muitas vezes as empresas que contratam deficientes somente para cumprir tabela, e acabam se impressionando com o desempenho destes, e percebe que o que falta mesmo para essas pessoas é a oportunidade, para demonstrar que a deficiência não limita sua capacidade, o que os limita é a própria sociedade ao discriminá-los.

Existem inúmeros exemplos de deficientes que se sobressaem quando colocados em funções adequadas. Deficientes auditivos e visuais, por exemplo, apresentam um nível de concentração elevado comparado ao de pessoas com essas funções sensoriais 'normais'. As experiências de inclusão de deficientes em algumas empresas já estão estimulando outras a adotarem a mesma atitude, pois têm gerado resultados bastante positivos. Porto (2014), esclarece que optar pela vertente de enxergar a surdez como um conceito de diferença e não como deficiência. Sua diferença não se restringe ao não ouvir, mas ao desenvolvimento de potencialidades psicológicas e culturais diferentes dos ouvintes, o que não interfere em sua capacidade cognitiva.

As empresas têm buscado se reinventar todos os dias, para atrair os bons olhos do consumidor, que está cada vez mais crítico e exigente. Muitas empresas têm reconhecido que a transparência é um fator bastante relevante na hora de divulgar a sua marca, e dos caminhos escolhidos para favorecer sua imagem é influir na transformação da sociedade. A chamada responsabilidade social e o impacto que empresa traz para mesma, impulsiona o consumo e favorece não só o meio social, mas o econômico, pois apresenta uma boa imagem. Para Rocha (2016), os problemas sociais são campos férteis para o desenvolvimento de 
negócios, uma vez que se pode simultaneamente satisfazer uma necessidade social e ao mesmo tempo servir sua instituição, transformando a resolução de problema social numa oportunidade para negócios.

Fernandes (2016) argumenta que, a correta prática da responsabilidade social pode melhorar o desempenho e a sustentabilidade a médio e longo prazo da empresa, proporcionando: valor agregado à imagem corporativa da empresa; motivação do público interno; vantagem competitiva; facilidade no acesso ao capital e financiamento; reconhecimento dos dirigentes como líderes empresariais; melhoria do clima organizacional, dentre outros.

Deste modo é perceptível, que um complementa o outro, e que todos podem se beneficiar com a inclusão, priorizando acima de tudo o respeito.

\section{METODOLOGIA}

Para Lakatos et al. (2017), a pesquisa pode ser considerada um procedimento formal com método de pensamento reflexivo que requer um tratamento científico e se constitui no caminho para conhecer a realidade ou para descobrir verdades parciais.

Aqui foi realizada pesquisa descritiva que, de acordo com Gil (2020), tem o objetivo de descrever as características de determinados grupos de pessoas ou fenômeno com a utilização de técnicas padronizadas de coleta de dados por meio de questionário e da observação sistemática.

Para Minayo et al. (2016), a pesquisa qualitativa é a busca de respostas para questões particulares, se preocupando com as ciências sociais e um nível de realidade que não pode ser quantificado, com um universo de significados, motivos, aspirações e atitudes que corresponde a um espaço mais profundo das relações, dos processos e dos fenômenos e que não pode ser reduzido à operacionalização de variáveis.

A pesquisa foi realizada em duas etapas: 1a etapa: esta foi realizada com visita in loco, com o auxílio de intérprete, entre os meses de setembro a novembro de 2019. Esta primeira etapa foi para verificar a estrutura do empreendimento, entender o perfil empreendedor e perceber $\mathrm{o}$ atendimento realizado pelos colaboradores da Gelateria 'Alfa; 2a etapa: foi realizada no período de março a junho, por plataforma virtual (Google Meet), com auxílio de intérprete, e, em algumas vezes, por chamada de vídeo pelo WhatsApp. As informações foram coletadas diretamente com o empreendedor Empresário e Gestor da 'Alfa'.

Para efeitos de anonimato e confidencialidade desta pesquisa, ficou decidido identificar o nome da empresa em questão de Gelateria Alfa.

\section{RESULTADOS E DISCUSSÃO}

Muitas pessoas acreditam que as pessoas surdas passam por muitas dificuldades ao longo de suas vidas, seja no aspecto social, psicológico e acadêmico, e associam que isso pode de alguma maneira afetar sua capacidade cognitiva. De fato, Empresário e Gestor, da 'Alfa', idealizador da 'Alfa', passou por todas essas dificuldades até chegar neste patamar, mas conseguiu superar suas limitações e perfurar a bolha de preconceito e opressão que a sociedade produz, demonstrando que o indivíduo surdo é um cidadão como 
qualquer outro, pagador de impostos, que produz e que consome também, muito mais que se encaixar, Empresário e Gestor da 'Alfa' buscou se destacar e fazer a diferença.

A mente humana não é um conjunto de capacidades específicas, cada uma das quais, de alguma forma, independe das outras e se desenvolve independentemente. Deste modo, entende-se que o aprendizado então é a aquisição de capacidades especializadas para pensar sobres várias coisas, e a surdez não interfere, desde que o indivíduo consiga desenvolver outras habilidades de comunicação e interação social. A surdez não torna o indivíduo mudo, ele apenas desenvolve a linguagem fonética e vocal, o fato de um surdo não falar e logicamente não poder ouvir, não impede que ele se comunique e compreenda o mundo ao seu redor, o seu cérebro funciona como qualquer outro, e é capaz de desenvolver outras percepções que o ouvinte não consegue, por observar mais afundo (HORA et al., 2019).

Empresário e Gestor da 'Alfa' reconhece que nasceu em condições econômicas favoráveis em comparação a muitos outros surdos no Brasil, sempre contou com apoio e investimento da família, que aceitou a surdez e buscou inseri-lo ao máximo na sociedade. A família é o primeiro grupo social de contato direto e cotidiano com indivíduo surdo, e aceitação desta condição é de suma importância para o desenvolvimento e formação dele. Com bom acompanhamento pedagógico, psicológico e assistencial, ele pôde aprender a língua de sinais e estudar como qualquer outra criança.

Segundo Saito (2016), os complexos esquemas espaciais do sinal na língua de sinais fazem como que os objetos e fenômenos estejam situados em um contexto esquemático de relações e localizações específicas que constituem sua gramática própria, ou seja, os surdos fazem o uso linguístico do espaço.

Sabe-se que o lema 'educação para todos', não passa de uma bonita teoria, o sistema público escolar brasileiro já é bastante defasado para as crianças comuns, para as surdas é quase inexistente. Na prática, as políticas ignoram as legislações e os termos de inclusão. Duarte (2019) fazem uma análise da situação da educação brasileira e apresentam a realidade do fracasso escolar: a educação brasileira é situada como a pior do mundo, há uma rigorosa seleção gerando um índice de reprovação no final da primeira série que beira os $50 \%$, os professores (mulheres) são discriminados e, assim por diante.

Essa exclusão não se dá exclusivamente ao sistema educacional público, existem muito poucas escolas particulares verdadeiramente inclusivas, das que existem, poucas oferecem um ensino de qualidade e especializado. Então mesmo tendo um poder aquisitivo relevante, a missão de inclusão e ensino da criança surda também é bastante complicada. Com todos esses fatores que podiam ter feito de Empresário e Gestor da 'Alfa' um adulto frustrado e conformado, ele cresceu pensando em maneiras de ser independente, mudar o mundo, oferecer oportunidades, levar motivação e ser referência para outros surdos. Foi professor voluntário de LIBRAS em uma comunidade surda e atualmente está graduando em Letras Libras - UFS e está quase se formando. Empresário e Gestor da 'Alfa' demonstra, que antes mesmo de empreender no ramo de gelatos, ele já empreendia sonhos, e a sua força de vontade, a ação propriamente dita, tem permitido que ele realize não somente sua satisfação pessoal, como a de muitas outras pessoas.

Como planejado, desde o princípio a contratação de colaboradores surdos foi efetivada. Atualmente a 'Alfa' conta com grande parte de colaboração surda, da produção ao atendimento, e o principal requisito 
exigido por Empresário e Gestor da 'Alfa' no processo de seleção e recrutamento é capacidade de atendimento ao cliente.

De acordo Menezes et al. (2017), é possível entender a surdez não como uma deficiência ou como uma anomalia que está impregnada no corpo de um determinado sujeito, mas como uma ação material que possui significados pelos diferentes grupos culturais.

A competência é a capacidade de envolver os saberes para dominar situações consistentes do trabalho e para veicular experiências adquiridas de uma situação concreta a outra. Em resumo, a qualificação de uma pessoa é a sua capacidade de resolver com velocidade e eficácia os problemas com certo grau de complexidade que aparecem durante o exercício de sua atividade profissional (MENEZES et al., 2017).

O objetivo é que exista um contato mútuo entre atendente surdo e cliente, como experiência da inclusão. Leite (2020) defende que o grupo de pessoas surdas se distingue dos outros grupos, no entanto, interagem com o mundo por meio de experiências visuais, exercendo o direito e a faculdade de apropriar-se da Língua de Sinais e, também, da Língua Portuguesa, o que permitirá o seu desenvolvimento como pessoa humana e sua circulação entre os contextos socioculturais. Para os colaboradores surdos os principais requisitos são: instrução em Libras, capacidade de se comunicar bem como segunda língua dos surdos, ter simpatia, senso de responsabilidade, esforço, entender bem de informática intermediária, facilidade de aprender e vontade de trabalhar. Para a minoria, que são os colaboradores ouvintes na 'Alfa', os requisitos são os mesmos e não há a exigência de nenhum certificado para ambos, usando apenas avaliações de qualificações e competências.

O treinamento é feito constantemente, pois Empresário e Gestor da 'Alfa' acompanha tudo de perto, corrigindo e orientando seus funcionários para desenvolver suas práticas, seus conhecimentos e suas posições. Quando não é feito de forma presencial, é utilizado um sistema que registra e apresenta os procedimentos do trabalho, o que facilita a aprendizagem do colaborador.

Sobre a questão de satisfação do cliente, de acordo com Kotler et al. (2012), a administração de marketing é definida como um esforço consciente para alcançar resultados de troca desejados com mercados-alvo. Apesar de ser um empreendimento com gestão e colaboração pessoas surdas, o atendimento é voltado para todos os públicos, objetivo é além de oferecer um sabor diferenciado de gelatos, é promover interação entre o cliente e o colaborador. Essa interação promove um reconhecimento do surdo pela sociedade, e comunicação mesmo que o cliente ouvinte não seja fluente na língua de sinais. O surdo se sente mais compreendido, e o ouvinte passa a enxergar a necessidade e a importância da inclusão em todos os ambientes de trabalho, pois consegue ver ali, que é possível.

Kotler et al. (2012) afirma ainda que dentro do grupo-alvo, pode-se identificar os clientes mais lucrativos e estabelecer ofertas mais atraentes para construir melhores relacionamentos com eles. Pode-se propor sistemas de pedidos automáticos, estabelecer sistemas de treinamento gerencial e consultivo e até mesmo patrocinar uma cadeia voluntária. Deste modo entende-se que mesmo sendo um segmento que atende todos os públicos, o gestor pode identificar quais tipos de consumidores mais frequentam, se são 
crianças, estudantes, executivos e deste modo oferecer produtos, serviços e promoções especiais para cada grupo.

Assim, diante das informações concedidas e observadas na Gelateria 'Alfa', os elementos levantados nos objetivos foram aqui discutidos e apresentados com resultados satisfatórios.

\section{CONCLUSÕES}

A Gelateria 'Alfa' surgiu, então, a partir de um desejo antigo de empreender. A princípio, Empresário e Gestor da 'Alfa' não imaginava vender o gelato italiano propriamente dito, pois possuía algumas ideias relacionadas ao ramo de açaí, mas após algumas pesquisas, ele pensou em fazer algo com paletas mexicanas, com o apoio do seu pai, eles decidiram viajar para São Paulo para aprimorar seus conhecimentos em alguns cursos, e lá ele teve a oportunidade de se capacitar e conhecer a tradição italiana e o ramo do gelato artesanal, ao obter esse conhecimento e ao experimentar os sabores, Empresário e Gestor da 'Alfa' ficou ansioso e admirado, decidiu então fazer a capacitação e logo após uma formação com um professor italiano, onde ele pôde aprender não somente sobre um produto que possa ser saboreado, mas mostrar para a sociedade e consumidores que um surdo pode empreender e que é possível gerar uma comunicação, seja ela em LIBRAS, gestual, mímica ou escrita.

A primeira gelateria foi inaugurada em 2016 em um local privilegiado próximo a orla de Aracaju - SE, mais precisamente na Coroa do Meio. Apesar de pequena, era muito bem estruturada, atraindo clientes de várias partes do estado e turistas, apresentando um conceito inovador de produto e negócio, isso porque além de Empresário e Gestor da 'Alfa', todos os seus colaboradores também são surdos, cujo mercado chama de empresa inclusiva. Para Empresário e Gestor da 'Alfa', trata-se de uma demonstração de que os surdos podem e são capazes de aprender e trabalhar com o que quiserem, que tem valor na sociedade, que pode empreender, que pode ter contato com o público e não ser apenas direcionados a subempregos.

Em relação às pessoas portadoras de deficiência, ainda que timidamente, observa-se que a sociedade está superando o preconceito, na tentativa de possibilitar-Ihes uma efetiva inclusão. O seu produto, a princípio inédito, apresenta uma técnica artesanal italiana, o sabor concentrado natural da fruta e uma textura totalmente diferente dos sorvetes tradicionais, o que agrada aos seus clientes.

Em 2017, a 'Alfa' foi reinaugurada na Treze de Julho, bairro nobre de Aracaju - SE, com uma estrutura maior e mais sofisticada, com mais colaboradores também surdos. O sucesso foi tão grande que Empresário e Gestor da 'Alfa' foi convidado para participar do Shark Tank Brasil, programa de TV que convida pequenos empresários para ouvirem suas histórias e suas ambições, e então selecionam as melhores propostas e fazem investimentos. Empresário e Gestor da 'Alfa' não foi selecionado, mas tornou-se reconhecido em todo país, atraindo clientes e admiradores de diversos lugares. Ele não desistiu do seu projeto, nem ficou desanimado por não ser selecionado, pelo contrário, desfrutou de toda sua 'fama' e a encarou como mais uma oportunidade de crescimento. Seu objetivo é abrir franquias por todo país, por enquanto ele já possui duas filiais em Aracaju, e está projetando a abertura da sua primeira franquia na capital baiana, Salvador - BA. É um negócio promissor e devidamente planejado. 


\section{REFERÊNCIAS}

AMARAL, L. A.. Mercado de trabalho e deficiência. Revista brasileira de educação especial. 2004.

BRASIL. Conhecendo nossos direitos e deveres: diretrizes internacionais. Rio de Janeiro: INES, 2001.

BRASIL. Lei 13.146 de 06 de julho de 2015. Institui a Lei Brasileira de Inclusão da Pessoa com Deficiência (Estatuto da Pessoa com Deficiência). Brasília: DOU, 2015.

BRAUM, L. M. S.; NASSIF, V. M. J.. Características individuais e propensão ao empreendedorismo: proposição de modelo teórico. Revista da Micro e Pequena Empresa, v.13, n.3, 2019.

DORNELAS, J. C. A.. Empreendedorismo: transformando ideias em negócios. 3 ed. Rio de Janeiro: Elsevier, 2012.

DUARTE, A. R.. A organização do trabalho pedagógico e seus desdobramentos frente ao processo de reprovação escolar. Dissertação (Mestrado Profissional em Educação Profissional e Tecnológica) - Instituto Federal de Educação, Ciência e Tecnologia do Amazonas, Manaus, 2019.

FERNANDES, C. I. M.. A sustentabilidade das organizações de economia social: o estudo de caso da sociedade filarmónica de apoio social e recreio artístico da amadora. Dissertação (Mestrado) - Instituto Universitário de Lisboa, Lisboa, 2016.

FRANCO, J. O. B.; GOUVÊA, J. B.. A cronologia dos estudos sobre o empreendedorismo. Revista de Empreendedorismo e Gestão de Pequenas Empresas, v.5, n.3, p.144-166, 2016.

GIL, A. C.. Métodos e técnicas de pesquisa social. São Paulo: Atlas, 2020.

GORCZEVSKI, C.; KONRAD, L. R.. A educação e o plano nacional de educação em direitos humanos: efetivando os direitos fundamentais no Brasil. Revista do Direito UNISC, Santa Cruz do Sul, n.39, p.18-42, 2013.

GUARINELLO, A. C.. A influência da família no contexto dos filhos surdos. J. Bras. Fonoaudiol., Curitiba, v.3, p.28-33, 2000.

HORA, L. C. L.; COSTA, N. S. A.; GOMES, N. S.. Aquisição da linguagem sob a perspectiva das inteligências múltiplas e da modularidade da mente. Caletroscópio, v.7, p.150-166, 2019.
KOTLER, P.; KELLER, K. L.. Administração de marketing. São Paulo: Pearson Education do Brasil, 2012.

LAKATOS, E. M.; MARCONI, M. A.. Metodologia do trabalho científico: projetos de pesquisa, pesquisa bibliográfica, teses de doutorado, dissertações de mestrado, trabalhos de conclusão de curso. São Paulo: Atlas, 2017.

LEITE, E. L.. Apropriação das libras por estudantes do curso de tradução e interpretação em libras/ língua portuguesa. Monografia (Licenciatura em Língua Brasileira de SinaisLibras/Língua Portuguesa) - Universidade Federal de São Carlos, São Carlos, 2020.

MARIUZZA, D. M.. O comportamento do consumidor na cidade de Guaporé/RS à luz do marketing de fidelização. Monografia (Bacharelado em Administração) - Universidade de Caxias do Sul, Guaporé, 2019.

MAZZOTTA, M. J. S.. Educação especial no Brasil: história e políticas públicas. São Paulo: Cortez, 2008.

MENEZES, R. D.; GRANDE, C.. As escritas surdas como artefatos culturais mediadores de reflexões a respeito das crenças sobre a surdez. Dissertação (Mestrado Profissional em Formação de Professores) - Universidade Estadual da Paraíba, Campina Grande, 2017.

MINAYO, M. C. S.; DESLANDES, S. F.; GOMES, R.. Pesquisa social: teoria, método e criatividade. In: Pesquisa social: teoria, método e criatividade. 2016. p.95.

PORTO, S. B. N.. Sou surdo e não sabia? Situação linguístico, cultural e educacional dos surdos em Sumé/PB e o processo de implantação da escola bilíngue no município. Tese (Doutorado em Educação) - Universidade Federal da Paraíba, João Pessoa, 2014.

RAIÇA, D.. Tecnologias para a educação inclusiva. São Paulo: Avercamp, 2008.

SAITO, D. S.. Ambientes de comunidades de prática virtuais como apoio ao desenvolvimento de neologismos terminológicos em língua de sinais. Tese (Doutorado em Engenharia e Gestão do Conhecimento) - Universidade Federal de Santa Catarina, Florianópolis, 2016.

SCHUMPETER, J. A.. Teoria do desenvolvimento econômico: uma investigação sobre lucros, capital, crédito, juro e o ciclo econômico. São Paulo: Abril Cultural, 1988.

A CBPC - Companhia Brasileira de Produção Científica (CNPJ: 11.221.422/0001-03) detém os direitos materiais desta publicação. Os direitos referem-se à publicação do trabalho em qualquer parte do mundo, incluindo os direitos às renovac̃os, expansões e disseminaç̃es da contribuiç̃o, bem como outros direitos subsidiários. Todos os trabalhos publicados eletronicamente poderão posteriormente ser publicados em coletâneas impressas sob coordenação da Sustenere Publishing da Companhia Brasileira de Produção Científica e seus parceiros autorizados. Os (as) autores (as) posteriormente ser publicados em coletâneas impressas sob coordenação da Sustenere Publishing, da Companhia Brasileira de Produção Cientifica e seus parce 